\title{
GESTÃO DE EVENTOS: ORIENTAÇÕES BÁSICAS PARA O CONTEXTO DAS UNIVERSIDADES
}

\author{
Andressa Aita Ivo \\ Universidade Federal de Santa Maria \\ dessaaita@gmail.com \\ Elizara Carolina Marin \\ Universidade Federal de Santa Maria \\ elizaracarol@yahoo.com.br \\ Lucas Machado De Souza \\ Universidade Federal de Santa Maria \\ lucasdesouza515@hotmail.com
}

RESUMO: O tema deste trabalho é Gestão de Eventos, e objetiva sinalizar orientações básicas para realização de eventos na esfera das Instituições de Ensino Superior, a partir do contexto da Universidade Federal de Santa Maria (UFSM), visando auxiliar os gestores e comissões organizadoras nas diferentes fases de realização, os setores responsáveis, respeitando as peculiaridades de cada Centro/Unidade e objetivos do evento. Sabemos que um guia de orientações básicas não é suficiente para garantir o êxito do evento, mas pode ser uma ferramenta para auxiliar os gestores e comissões a diminuir dificuldades e percalços, dada a complexidade que evolve a gestão de eventos.

Palavras-chave: Evento. Gestão. orientações 


\section{Introdução}

A gestão de eventos apresenta-se como uma área emergente no entanto, em âmbito nacional, a produção acadêmica ainda é incipiente, o que realça a importância de investigar como se dá o processo de gestão de um evento. Nunes $(2006$, p.5) reconhece que não existe um conceito geral utilizável para todos os processos da Gestão de um evento, mas entende que "deve apresentar um conjunto de tarefas que procuram garantir a realização eficaz de todos os recursos disponibilizados pela organização, a fim de serem atingidos os objetivos pré-determinados". Nessa direção, este estudo objetiva propor orientações básicas para a gestão de eventos na esfera das Universidades, a partir do contexto da Universidade Federal de Santa Maria (UFSM).

Cabe destacar que, geralmente, os eventos se baseiam em um caderno de encargos com os requisitos a serem cumpridos pela instituição promotora. O caderno de encargos é um material elaborado pela comissão principal que visa à organização e descreve os passos a serem seguidos pelo órgão que realizará o evento, de maneira que não haja alterações durante sua realização e, simultaneamente, garanta que o evento seja desenvolvido conforme os passos preestabelecidos. Aopção pela proposta de orientações básicas ${ }^{1}$ deriva da possibilidade de as Unidades que compõem as Universidades realizarem adequações conforme as necessidades e particularidades do evento. Trata-se de um instrumento para facilitar a operacionalização de eventos no âmbito das universidades.

Poucas Instituições de Ensino Superior possuem um guia ou manual de orientações para gestão de eventos em suas dependências; cabe destacar o caso da Rede Federal de Educação Profissional e Tecnológica, que elaborou, em 2010, um Guia de Eventos, Cerimonial e Protocolo, que tem por finalidade contribuir para a padronização dos eventos que acontecem nas instituições que compõem a Rede. Contudo, o Guia prioriza eventos solenes, tais como: colação de grau, solenidades de formaturas, aula magna, aula inaugural, solenidades de posse, inaugurações e outorga de títulos honoríficos, sem maiores especificações para demais eventos. As Universidades quea presentam guias ou manuais também priorizam os eventos solenes, e não há referência quanto à organização de outros

${ }^{1}$ As orientações básicas foram elaboradas tendo como referência o Centro de Educação Física e Desportos (CEFD). 
eventos, bem como sobre os trâmites burocráticos e quais setores devem ser contatados. No caso específico da UFSM, não há referência sobre normativas para a organização de eventos, apenas a normativa n. ${ }^{\circ}$ 01/2012/PROGRAD, que complementa a Resolução 012011, sobre as cerimônias de formatura da UFSM.

Entendemos a Universidade como instituição social, centrada na formação e democratização, via princípio da indissociabilidade entre ensino, pesquisa e extensão, entre teoria e prática social, na busca pela interpretação da realidade e promoção da emancipação humana. Como não está descolada da estrutura e do funcionamento da sociedade como um todo, vivencia permanentemente conflito entre posições e projetos (CHAUI, 2003).

Em função de a Universidade congregar diferentes cursos de graduação, a pesquisa, a pós-graduação, e a extensão, há promoção anual de inúmeros eventos de natureza diversa. Normalmente, as Universidades não possuem um setor especializado de Gestão de eventos, ficando a organização desses a cargo de docentes e discentes de cada Unidade Universitária, que, muitas vezes, recorrem a empresas privadas ${ }^{2}$ especializadas nesse setor. O que reforça a necessidade de elaboração de orientações básicas, respeitando a autonomia da Unidade Universitária e as especificidades da tipologia e objetivo de cada evento.

Para a consecução deste estudo, lançamos mão de análise documental e de pesquisa de campo. Conforme Cellard (2010), a análise documental possibilita o alcance de fatos que enriquecem o que é contado pelos sujeitos. Serviram como suporte as informações do Portal da UFSM, sobretudo, os links: da Pró-Reitoriade Infraestrutura e da Pró-Reitoria de Planejamento, por serem as que estão diretamente envolvidas com a organização da parte física do evento; dos Órgãos Suplementares (que envolvem os meios de comunicação/ divulgação e de alimentação) da UFSM, tais como TV Campus, Rádio Universidade, Multiweb; e das Unidades Universitárias (que englobam o CEFD e demais Centros que poderão colaborar com a gestão e realização do evento).

Para complementar e detalhar elementos e informações, realizamos pesquisa de campo que, para Minayo (2007, p.61),"permite a aproximação do pesquisador da realidade sobre a qual formulou uma pergunta, mas também estabelecer uma interação entre os 'atores' 
que conformam a realidade (...)". Essa etapa compreendeu a visita em diversos setores da UFSM, necessários para a realização de eventos, tais como: Pró-Reitorias; Departamento de Material e Patrimônio (DEMAPA); e o Centro de Educação Física e Desportos, para elementos referentes a registro (Gabinete de Projetos/GAP) e aprovações (Colegiado do Departamento e Conselho de Centro) do projeto.

\section{Eventos}

Os eventos assumem papel importante na promoção do conhecimento, da instituição, do lazer, da cidade, do turismo, ou seja, na promoção social, cultural, política e econômica. Inúmeros são os tipos de eventos e suas formas de organização pelo mundo, por isso não há como compreendê-los de forma estática e fechada. Na acepção de Britto e Fontes (2002, p. 20), "evento é a soma de esforços e ações planejadas com o objetivo de alcançar resultados definidos junto ao seu público-alvo". Consiste numa atuação profissional que envolve pesquisa, planejamento, organização, coordenação, controle e implantação de um projeto, visando atingir o seu público-alvo com medidas concretas e resultados projetados.

Cada evento tem características próprias, o que inviabiliza um modelo padrão a ser seguido. O planejamento prévio depende do que se quer alcançar e dos recursos financeiros disponíveis, o que requer ação ponderada, realista e criativa. Alguns eventos propõem-se a contribuir com legados para a comunidade/cidade/instituição em que foi realizado o evento.

Normalmente, a gestão de um evento é composta por fases, com um passo a passo que norteia a comissão organizadora antes, durante e após o evento. Martin (2003) considera que, independentemente do evento, desde sua abrangência até suas classificações e tipologias, todos contemplam três fases diferentes: Pré-evento, Evento e Pós-evento. O Pré-evento é a fase que compreende a ideia inicial do projeto e seu planejamento prévio, incluindo todas as atividades a serem desenvolvidas, profissionais a serem contratados, os gastos e as despesas. Realiza-se a partir da definição dos objetivos gerais e específicos. Se bem estruturada - esta fase -, o evento tem potencial de ser realizado sem muitos percalços. O Evento é a fase que compreende: a execução do planejado no Pré-evento; a montagem da estrutura necessária para sua realização; e execução do trabalho das partes contratadas no pré-evento. O Pós-evento contempla: prestação de contas; desmontagem 
da estrutura realizada na fase anterior; devolução do material; acerto de honorários dos fornecedores e parceiros do evento. É de extrema importância a avaliação geral do evento, apontando os erros e os acertos para garantir melhoria das ações, dos resultados e da qualidade de outros eventos.

Há na bibliografia diferentes formas de classificação para eventos. Martin (2003), em seus estudos, descreve nove formas: por abrangência; para competição; para demonstração ou exposição; por data ou frequência; por categoria e função estratégica; por sua dimensão; por objetivo ou área de interesse; pelo perfil dos participantes; e por tipo de adesão.

Quanto à tipologia, existem inúmeros tipos de eventos capazes de atender às necessidades e aos objetivos específicos de qualquer natureza.

No âmbito das universidades, as tipologias mais recorrentes de eventos institucionais são: programas de visitas; exposição; jornada; feira; conferência; videoconferência; palestra; simpósio; painel; mesa redonda; convenção; congresso; seminário; fórum; debate; semana; workshop; e oficina.

Os passos que seguem a classificação e a tipologia do evento são: definir as comissões organizadoras do evento com as referidas funções e a construção do checklist do material necessário para a efetivação do evento.

\section{Gestão de Eventos}

Fazendo-se referência ao latim, o termo Gestão tem sua origem na palavra gestione, que se refere à prática de gerir, gerenciar, administrar. Entendemos, a partir de Chiavenato (2000, p. 6-7), que administração significa:

Interpretar os objetivos propostos pela organização e transformá-los em ação organizacional por meio do planejamento, organização, direção e controle de todos os esforços realizados em todas as áreas e em todos os níveis da organização, a fim de alcançar tais objetivos da maneira mais adequada à situação.

O gestor assume papel fundamental na Gestão de eventos, sendo responsável por todo o processo que envolve a sua construção, levando em conta uma série de fatores (tipologia do evento, estrutura, equipe de trabalho, ambiente, tarefas etc.) que pode determinar o sucesso ou o fracasso de um evento. Maximiano (2002, p.182) afirma que "a responsabilidade do gestor é assegurar a realização do projeto dentro dos padrões de 
desempenho da missão, prazo e custo, o que exige a administração de comunicação, recursos humanos, contratos, materiais e riscos".

Categoricamente, afirma-se que não há um sistema de regras universais para o desenvolvimento de um determinado evento, pois se deve levar em conta que cada evento tem um formato próprio e uma tipologia que varia de acordo com a necessidade dos grupos sociais.

Para evitar futuros percalços, o Gestor necessita planejar os passos a serem realizados antes, durante e após o evento. Invariavelmente, o planejamento de eventos possui relação direta com os objetivos que se deseja alcançar com a sua realização. Portanto, é necessário defini-los, com precisão, a fim de que os resultados obtidos sejam os previstos.

Planejar um evento leva tempo e dedicação, porém, todo tempo investido refletirá no próprio evento, reduzindo riscos de desacordo com o esperado. Poit (2006) reforça que quanto mais detalhado o planejamento, maiores são as chances de obter sucesso e alcançar os objetivos. O autor propõe um modelo de planejamento básico que aponta questões-chave para a realização de um evento, tais como: quê?; quem?; quando?; onde?; por quê?;como?; quanto? (custo) e quanto? (quantidade de pessoas). Na elaboração de um planejamento criterioso, esses questionamentos podem se traduzir nos seguintes elementos: objetivos; públicos; estratégias; recursos; implantação; fatores condicionantes; avaliação e orçamento.

Nessa etapa, outro aspecto fundamental a se considerar, é o nome do evento, visto que esse deve exprimir seus objetivos e ser de fácil assimilação pelo público-alvo. Geralmente, a denominação do evento contempla, inicialmente, o número de série, a metodologia de trabalho e a abrangência (BRASIL, 2012).

Toda gestão envolve não só um Gestor, mas também uma equipe preparada para executar funções, bem como para dar o feedback daquilo que está sendo feito. Todavia, para constituir a equipe, devemos considerar a motivação e a responsabilidade dos integrantes, pois, assim como suas funções, ela passa a ser parte do todo (não somente cumpridora de ordens) e repercute diretamente no andamento e resultado do evento.

Um gestor precisa ter a habilidade de antecipar possíveis falhas na estrutura final de um evento, ou seja, a capacidade de prever situações, tais como: condições climáticas, atrasos, 
questões de segurança, iluminação, entre outros. De modo geral, o Gestor apresenta características de liderança nos desafios que se apresentam durante a promoção de um determinado evento, consoante aos atributos como determinação, motivação, carisma, poder de criação, inovação, que facultam o sucesso do evento além de habilidade para gerenciar os recursos, pois nenhum tipo de evento é possível de se realizar sozinho. Tais elementos sinalizam que gerenciar um evento não é tarefa fácil.

\section{Orientações Básicas}

Vale lembrar que a definição de data e local do evento é uma das ações mais difíceis, no entanto, das mais importantes a serem realizadas e, em grande medida, determina o êxito e a qualidade do evento. Nesse sentido, alguns elementos devem ser observados, para definir a data, tais como: a disponibilidade do local e da equipe responsável pela organização e execução, observando os prazos necessários para montagem e desmontagem da infraestrutura; a agenda dos palestrantes, conferencistas e demais pessoas que integram as atividades previstas na programação; a adequação da data e horário às características do público-alvo; se há eventos concorrentes ou feriados na mesma data ou em datas muito próximas. E, para definir o local, considerar: a estimativa do número de participantes; infraestrutura de hospedagem e alimentação; a facilidade de acesso ao local do evento (transporte, estradas e rodovias, estacionamento); a acessibilidade para pessoas com dificuldade de locomoção; as condições técnicas e operacionais para utilização de recursos audiovisuais (BRASIL, 2013).

Tendo em vista os aspectos já mencionados para a definição do local do evento, uma visita técnica contribui para conhecer as facilidades, as limitações do espaço, para identificar as melhorias necessárias e o que será, de fato, viável realizar.

A realização de um evento requer o engajamento de profissionais com diferentes habilidades e perfis e de um grande coletivo de pessoas pensando e executando as ações de modo mais intenso nos dois meses que antecedem ao evento, durante e, no mínimo, uma semana posterior a sua realização. O coletivo envolvido é dividido por comissões consoante com o evento pretendido, isto é, cada evento apresenta características particulares, e isso terá reflexo nas comissões a serem definidas. Para tal, as providências são: definir 
o coordenador do evento (ou a equipe coordenadora) e congregar os profissionais de apoio, para, de acordo com a formação, habilidades e disponibilidade, subdividi-los entre as comissões, bem como atribuir as responsabilidades e definiras metas. Todas as ações demandam sistematização e definição de prazos, permitindo às comissões monitorar o andamento, as pendências, as dificuldades, adotar soluções e, fundamentalmente, ter uma noção mais abrangente da construção do evento.

No processo de organização de eventos há desafios e imprevistos, o que requer dos envolvidos dedicação, criatividade, coesão e uma visão estratégica. É essencial que cada integrante tenha ciência de suas atribuições e dos prazos a cumprir.

A composição da equipe de trabalho varia de acordo com as especificidades do evento, e todos os envolvidos devem estar capacitados para as tarefas que forem demandadas. $\mathrm{Na}$ sequência, apontamos algumas comissões centrais -com base em Poit (2006) -, com suas respectivas funções e infraestrutura material para dar conta da execução:

Comissão central organizadora: responsável pela organização geral do evento e onde precisa(m) estar situado(s) o(s) Coordenador(es) ${ }^{3}$ do evento. A Comissão Central é responsável por dar suporte a todas as outras comissões e ter efetivo suficiente para que possa ser facilmente contatada. Essa comissão deverá criar uma sede de atuação para a organização do evento, em outras palavras, uma secretaria que contemple recepcionista e/ou técnicos-administrativos e os materiais de expediente de um evento que possam vir a ser solicitados pelas demais comissões. Trata-se de um espaço de circulação e trocas de informações entre as comissões, bem como de compreensão e viabilização das ações.

Comissão de infraestrutura: responsável pela tramitação burocrática dentro da universidade, quanto às autorizações, liberações e reservas referentes aos espaços e materiais do evento; elaboração dos mapas e placas de sinalização; organização e montagem do espaço de realização do evento; e providência de itens como pirâmide, fechamento em lona, tablado, palco com escada de acesso, serviços de limpeza, mesas e cadeiras, sonorização, serviço de jardinagem, contratação audiovisual, praça de alimentação e estacionamento, entre outros.

\footnotetext{
${ }^{3}$ Para eventos de pequeno porte, um profissional costuma ser suficiente para responder pela coordenação. Já para iniciativas com maior grau de complexidade, é preciso destacar um grupo de profissionais para coordenar as atividades (BRASIL, 2013).
} 
Comissão de informática: responsável pela manutenção e atualização da página do evento; criação de e-mail para o evento e ações referentes este; divulgação na página da Universidade, da Unidade Universitária proponente e em demais meios de comunicação (blogs, páginas em redes sociais etc.).

Comissão de recepção, solenidades e credenciamento: responsável por elaborar a lista de convidados, de participantes e de confirmações; pela recepção dos convidados (com nome, horário de chegada, número de vôo, hotel a serem hospedados, telefone de contato etc.); por organizar e executar o cerimonial de abertura e encerramento do evento, com a listagem das autoridades; por contratar o mestre de cerimonias e elaborar o roteiro cerimonial; por organizar mastros e bandeiras; pelo processo de credenciamento dos participantes já inscritos, inscrições no ato e a entrega de material individualizado (pastas, caneta, blocos de anotações etc.); além de ser ponto de referência para informações durante o evento.

Comissão de segurança e hospitalar: responsável por entrar em contato com os órgãos públicos para garantir tanto segurança (tais como bombeiros, polícia militar) quanto pronto atendimento e bem-estar (a exemplo de agentes de saúde, ambulância, isolamento da área, estudos de impacto sonoro). Cabe a essa comissão providenciar também: gerador de energia, materiais de primeiros socorros e rádio de comunicação.

Comissão de relações públicas e marketing: responsável pela identidade visual do evento; pelo envio de convites e contato com os participantes e com a mídia; pela divulgação do evento; pelo contrato do fotógrafo e de equipe de filmagens e de informática; pela elaboração do material gráfico etc. É de responsabilidade dessa comissão a confecção dos seguintes itens: convites, cartazes, banners de divulgação, flayers, outdoor, ficha de inscrição, crachás, certificados, ficha de avaliação, camisetas, pastas e blocos de anotações. Essa comissão pode ser assessorada, no caso da UFSM, pela "Agência FACOS"4.

Comissão de hospedagem e alimentação: responsável pela hospedagem dos participantes, pelo coffee break e refeições dos participantes.

Comissão de finanças: responsável pelo orçamento geral do evento, pelas fontes de recursos e pelo relatório de prestação de contas.

${ }^{4}$ A Agência oportuniza a prática publicitária orientada a partir da criação de campanhas de divulgação para ações e eventos que aconteçam no âmbito ou com participação da UFSM, compreendendo Pró-Reitorias, Órgãos Executivos, Suplementares e Unidades Universitárias, além de entidades sem fins lucrativos ou de interesse dos cursos de Comunicação Social da Instituição, a partir de atividades curriculares ou projetos. Para maiores informações, acessar <http://w3.ufsm.br/facos/?page_id=122)>. 
Comissão de transporte: responsável pelo translado dos participantes, contato com as agências de viagem e compra de passagens aéreas e terrestres, e pela listagem de passageiros, entre outros.

Comissão cultural: responsável pelo contato e contrato de grupos artísticos e oficinas, por organizar os horários das apresentações, conforme o cronograma do evento.

As comissões são únicas sobre as suas responsabilidades; todavia é fundamental a comunicação entre elas durante todo o processo de organização e realização do evento. Atualmente, os eventos de grande e menor proporção podem contar com sistemas de comunicação avançados (pagers, walktalk, rádios de comunicação, sistemas de painéis digitais, entre outros) que facilitam o desenvolvimento das ações.

A seguir, destacamos os setores e Unidades da UFSM a serem contatados para a gestão do evento.

\section{Setores e Unidades da UFSM}

Para melhor visualização, os quadros estão organizados de modo a especificar o setor responsável (Pró-Reitoria, Unidade Universitária ou Órgãos Suplementares, conforme organização exposta no Portal da UFSM) e a comissão responsável pelos contatos, a fim de garantir o serviço prestado pelos setores e Unidades.

A Unidade Universitária terá papel fundamental na realização do evento. Para que este ocorra, exige-se: registro no Gabinete de Projetos (GAP); aprovação no Colegiado do Departamento do professor coordenador do projeto; e aprovação pela Unidade Universitária. Tudo realizado com antecedência, no intuito de garantir recursos e espaços necessários para a sua consecução.

De modo geral, cabe às Unidades Universitárias a liberação dos espaços físicos e a limpeza interna (banheiros, hall de entrada, calçadas etc.) do local. Em determinados casos, há necessidade de alocar o evento no calendário acadêmico do Centro, mas isso só será consolidado após conclusão das devidas aprovações. 


\begin{tabular}{ll}
\hline UNIDADE UNIVERSITÁRIA & COMISSÕES RESPONSÁVEIS \\
\hline Registro no GAP & Comissão Central Organizadora \\
Aprovação do Departamento & Comissão Central Organizadora \\
Aprovação no Conselho & Comissão Central Organizadora \\
Liberação dos espaços & Comissão de Infraestrutura \\
Limpeza interna e serviços gerais & Comissão de Infraestrutura \\
Calendário Acadêmico & Comissão Central Organizadora
\end{tabular}

A Reitoria da UFSM está organizada e subdividida em Pró-Reitorias. A Pró-Reitoria de Infraestrutura é a responsável por todas as questões de infraestrutura necessárias para a realização de qualquer tipo de evento.

As comissões responsáveis pelos serviços de infraestrutura deverão entrar em contato com a PROINFRA e realizar os devidos procedimentos para que os itens definidos sejam garantidos para a realização do evento.

\begin{tabular}{ll}
\hline \multicolumn{1}{c}{ PROINFRA } & COMISSÕES RESPONSÁVEIS \\
\hline Eletricidade & Comissão de Infraestrutura \\
Encanamento & Comissão de Infraestrutura \\
Jardinagem & Comissão de Infraestrutura \\
Estacionamento & Comissão de Infraestrutura \\
Vigilantes & Comissão de Infraestrutura \\
Limpeza externa & Comissão de Infraestrutura \\
Reserva do Centro de Eventos & Comissão de Infraestrutura \\
Transporte terrestre & Comissão Transporte e Alimentação \\
Praça de alimentação & Comissão Transporte e Alimentação
\end{tabular}

Todo evento necessita de sistemas de internet, comunicação e mídia. No caso da UFSM, as comissões devem procurar - para dar suporte e assistência antes, durante e após o evento - os seguintes órgãos suplementares: MULTIWEB ${ }^{5}$,Centro de Processamento de Dados/CPD; Rádio Universidade; TV Campus.

Acerca deste trabalho, a Comissão de Informática terá a incumbência de contatá-los e apresentar a proposta do evento para que haja divulgação massiva do evento, visando alcançar o maior número de pessoas por meio de blogs e sites (do Centro promotor do evento, da UFSM e demais canais de divulgação); lembrando que a divulgação do evento deve acontecer com antecedência, promovendo expectativa e curiosidade na população.

\footnotetext{
${ }^{5}$ Trata-se de um setor junto àUFSM, que desenvolve diversos serviços para a realização de eventos, tais como: criação de site, transmissão digital via internet ao vivo, filmagens e fotografia, videoconferência etc. Para outras informações, acessar <http://www.multiweb.ufsm.br/>.
} 
MULTIWEB

Criação do site do evento

Transmissão digital via internet

Filmagem do evento

Fotografia

Serviço de internet para o evento
COMISSÕES RESPONSÁVEIS

Comissão de Informática.

Comissão de Informática.

Comissão de Informática.

Comissão de Informática.

Comissão de Informática.

Conforme Nakamura (2009), o rádio é indicado como um meio principal ou complementar em uma campanha, pois alcança uma grande quantidade de receptores, incluindo ambientes domésticos, profissionais, carros e dispositivos móveis (rádios portáteis, celulares e outros aparatos). Nessa direção, a Rádio Universidade ${ }^{6}$ pode assumir a responsabilidade de divulgar e realizar a cobertura do evento; a Comissão de RP terá como função específica passar o material do evento aos responsáveis da Rádio, para que ele seja divulgado à comunidade acadêmica e demais ouvintes.

RÁDIO UNIVERSIDADE

Divulgação do evento

Transmissão do evento
COMISSÕES RESPONSÁVEIS

Comissão de Relações Públicas e Marketing

Comissão de Relações Públicas e Marketing

Além das divulgações nas redes de internet e na Rádio Universidade, outro órgão da UFSM leva destaque no assunto: a TV Campus ${ }^{7}$. Classificada como órgão suplementar da Universidade, a TV Campus tem sua programação voltada à divulgação do ensino, pesquisa e extensão da instituição, além de servir como instrumento para compartilhar conhecimentos entre professores, alunos, servidores e comunidade em geral.

Caberá à Comissão de Relações Públicas e Marketing o contato com os responsáveis pelo setor, a fim de divulgar em sua programação o Evento proposto, como também fazer sua cobertura durante a sua realização.

TV CAMPUS

Divulgação do evento

Transmissão do evento
COMISSÕES RESPONSÁVEIS Comissão de Relações Públicas e Marketing

Comissão de Relações Públicas e Marketing

${ }^{6}$ Informações obtidas em <http://coral.ufsm.br/radio/>.

${ }^{7}$ Informações obtidas em <http://w3.ufsm.br/tvcampus/apresentacao.php>. 
Em virtude de o evento ser realizado no interior de uma universidade pública, todo material e serviços prestados que provierem de entidades externas à UFSM devem passar pelos chamados "processos licitatórios". Trata-se de uma espécie de competição entre empresas que concorrem por meio de modelos de licitações previamente estabelecidos, em que o preço de seus produtos são elementos fundamentais para a aquisição do serviço por parte da administração pública. O Departamento de Material e Patrimônio (DEMAPA) ${ }^{8}$, na UFSM, é o órgão responsável pelos processos de licitação. Assim, para orientações sobre procedimentos na contratação de outros serviços, as comissões devem entrar em contato como esse órgão.

\section{DEMAPA}

Processos Licitatórios

COMISSÕES RESPONSÁVEIS Conforme a demanda das comissões

As orientações básicas aqui propostas trazem os principais passos a serem seguidos para a gestão de um evento no contexto da UFSM. Contudo, de acordo com as especificidades do evento, poderá surgir a necessidade de contatar outros setores e unidades da Universidade.

\section{Considerações Finais}

A realização de eventos de diferentes naturezas é recorrente no contexto das Universidades. Contudo, poucas Instituições de Ensino contemplam Guias ou Manuais para sua operacionalização. Quando há, são específicos para atos solenes, sem menção à organização de outros tipos de eventos.

Tendo em vista a dinâmica multifacetada dos eventos e a complexidade que envolve a sua gestão, na maioria das vezes, os gestores no âmbito das Universidades não possuem formação e conhecimentos específicos para tal. O que, em geral, tem resultado na contratação de empresas privadas, especializadas na área de produção de eventos.

Sabemos que orientações básicas não são suficientes para garantir o êxito do evento, mas pode ser uma ferramenta para auxiliar os gestores e as comissões a minimizarem

\footnotetext{
${ }^{8}$ Trata-se de um órgão executivo da Administração Superior, na área de material e Patrimônio, subordinado à Pró-Reitoria de Administração. Tem por finalidade coordenar, dirigir e executar as atividades relativas a licitações destinadas à aquisição de material, contratações de serviços e importações, controle patrimonial de bens móveis e imóveis, manutenção de estoques de material de consumo e sua distribuição a todas as subunidades, de acordo com a legislação vigente (Disponível em: <http://sucuri.ufsm.br/portalweb/conteudo/ depto_map_pat.php>).
} 
dificuldades e percalços, dada a complexidade que evolve a idealização, organização, execução e avaliação de eventos. E, em última instância, um recurso para garantir a autonomia da Universidade.

Revista Kinesis, ed. 32 vol 2, jul-dez de 2014, Santa Maria. 


\section{Referências}

BRASIL. Instituto Federal de Educação, Ciência e Tecnologia do norte de Minas Gerais. Guia de Eventos, Cerimonial e Protocolo. Brasília: 2012. Disponível em: <http://www. ifsudestemg.edu.br/webfm_send/1563>. Acesso em: 05/06/2014.

. Instrução Normativa N. 01/2012/PROGRAD de 02 de abril de 2012.

Disponível em: <http://w3.ufsm.br/prograd/normativas/instrucao_normativa_01_2012_ prograd_formaturas.pdf>. Acesso em: 07/04/2014

BRITTO, Janaina; FONTES, Neno. Estratégias para Eventos: uma ótica de marketing e do turismo. São Paulo: Aleph, 2002.

CELLARD, André. Aanálise documental. In: POURPART, J. et al. A pesquisa qualitativa: enfoques epistemológicos e metodológicos. Petrópolis (RJ): Vozes, 2010.

CHAUÍ, Marilena. Sociedade, Universidade e Estado: autonomia, dependência e compromisso social. Seminário: Universidade: Por que e como reformar? Ministério da Educação, 2003. Disponível em: <http://www.ufv.br/reforma/doc_ru/MarilenaChaui.pdf>. Acesso em: 13 de abril de 2014.

CHELLADURAI, Packianathan. Sport management: defining the field.European Journal for Sport Management, [S.I.], v.1, p.7-21, 1994.

CHIAVENATO, Idalberto. Introdução à teoria geral da administração. 6. ed. - Rio de Janeiro: Campus, 2000.

FONSECA, João José Saraiva da. Metodologia da pesquisa científica. Fortaleza: UEC, Apostila, 2002.

MARTIN, Vanessa. Manual prático de eventos/ Vanessa Martin. São Paulo: Atlas, 2003.

MATIAS, Marlene. Organização de eventos: procedimentos e técnicas. - 5. Ed. Barueri, SP: Manole, 2010.

MAXIMIANO, Antonio Cesar Amaru. Administração de Projetos: como transformar ideias em resultados. $2^{\mathrm{a}}$ ed., São Paulo: Atlas, 2002.

MINAYO, Maria Cecília de Souza; DESLANDEZ, Suely Ferreira; GOMES, Romeu. (Orgs). Pesquisa social: teoria, método, criatividade. 25 ed. Petrópolis (RJ): Vozes, 2007. 
NAKAMURA, Rodolfo. Mídia: como fazer um planejamento de mídia na prática I Rodolfo Nakamura. São Paulo: Farol do Forte, 2009.

NUNES, Paulo. Conceito de Gestão e de Gestor. 2006. Disponível em: <http://www. notapositiva.com/trab_professores/textos_apoio/gestao/01conc_gestao.htm>. Acesso em: 03/06/2014.

POIT, Davi Rodrigues. Organização de eventos esportivos. São Paulo: Phorte, 2006.

SIMÕES, Roberto Porto. Relações Públicas: função política. São Paulo: Summus, 1995.

SANTA MARIA. Universidade Federalde Santa Maria - AGÊNCIA FACOS - Disponível em: <http://w3.ufsm.br/facos/?page_id=122>. Acesso em: 22/12/2013.

. Centro de Educação Física e Desportos -. Disponível em: <http://w3.ufsm.br/ cefd/>.Acesso em: 23/10/2013.

. Departamento de Material e Patrimônio. Disponível em: <http://sucuri.ufsm.br/ portalweb/conteudo/depto_map_pat.php>. Acesso em: 27/11/2013.

Multiweb. Disponível em: <http://www.multiweb.ufsm.br/>. Acesso em: $27 / 11 / 2013$

.Pró-Reitoriade Infraestrutura. Disponível em: <http://jararaca.ufsm.br/websites/ prefeitura/d6d7381b7f53e5ec8b00fc539d642060.htm>. Acesso em: 27/11/2013.

.Pró-Reitoria de Planejamento. Disponível em: <http://w3.ufsm.br/proplan/>. Acesso em: 27/11/2013.

.Rádio Universidade. Disponível em: <http://coral.ufsm.br/radio/>. Acesso em: $27 / 11 / 2013$

. TV CAMPUS. Disponível em: <http://w3.ufsm.br/tvcampus/apresentacao.php>. Acesso em: 27/11/2013.

Universidade Federal de Santa Maria. Disponível em: <http://www.ufsm.br/>. Acesso em: 27/11/2013. 


\section{GESTIÓN DE EVENTOS: DIRECTRICES BÁSICAS PARA EL CONTEXTO DE LAS UNIVERSIDADES}

RESUMEN: El tema de este trabajo es de Gestión de Eventos y tiene como objetivo señalar directrices básicas para la realización de eventos en el ámbito de las instituciones de educación superior, a partir del contexto, de la Universidad Federal de Santa Maria (UFSM), para ayudar a los administradores y los comités organizadores en las diferentes fases de logro, los sectores responsables, respetando las peculiaridades de cada centro / unidad y los objetivos del evento. Somos conscientes de que las directrices básicas no es suficiente para garantizar el éxito del evento, pero puede ser una herramienta para ayudar a los administradores y los comités de disminuir las dificultades y contra tiempos debido a la complejidad que se desarrolla organización de eventos.

Palabras clave: Evento. Gestión. directrices básicas.

\section{EVENT MANAGEMENT: BASIC GUIDELINES FOR THE CONTEXT OF UNIVERSITIES}

ABSTRACT: The theme of this work is Event Management and it objectives to signalize basic orientations for the realization of events in the sphere of Higher Education Institutions, from the context of the Federal University of Santa Maria (UFSM), to assist managers and organizing committees in the different phases of achievement, the responsible sectors, respecting the peculiarities of each Centre / Unit and objectives of the event. We know that a guide of basic orientations isn't sufficient to ensure the success of the event, but it can be a tool to assist managers and committees to decrease difficulties and mishaps due to the complexity involved in event management.

Palavras chaves: Event; Management; Guidelines 